\title{
A Deconstruction of Wittgenstein
}

Cynthia Willett-Shoptaw

University of Texas at Austin

In the Preface to Philosophical Investigations, a dissatisfied Wittgenstein reflects back upon his text as "a number of sketches of landscapes," or unfinished remarks about many philosophical subjects.' Wittgenstein uses the album metaphor to suggest that the sketches are fitted together as a composite view of language: "The satne or ulmost the same points are always being approached afresh from different directions, and new sketches made. Very many of these were badly drawn or uncharacteristic, marked by all the defects of a weak draughtsman. And when they were rejected a number of tolerable ones were left, which now had to be arranged and sometimes cut down, so that if you looked at them you could get a picture of the landscape. Thus this book is really only all ablum" (p. $v)$. Yet though the preface records a dissapointment with the text to follow, the fallure is taken to be one of skill, the defect of the draughtsman, and not of the project itgelf.

The sketches try to depict an alledgedly serious disorder found in philosophical discourse. It is the philosopher's task to treat this disorder: "The philosopher's treatment of a question is like the treatment of an 11lness" (sec. 255). One symptom of this illness is displaced expressions: "When philosophers use a word . . one must always ask oneself: is the word ever actually used in this way in the language-game which is its orignial home" (sec. 116). Wittgenstein's attempts to retnind us of the proper context for our words are, however, more than therapeutic technique since in order to locate the cause of bad philosophy in an incorrect view of language, he also sketches a correct view of language. ${ }^{2}$

The Investigations begins its therapy on a passage by st. Augustine. The preface, however, has us begin the book earlier, with the illusions of the Tractatus: the Investigations can "be seen in the right light only by contrast with and against the background of my old way of thinking" (p. vi). Let us recall then, some important statements from the Tractatus' picture theory of meaning: "A proposition is a picture of reality." "One name stands for one thing, another for another 
thing, and they are combined with one another. In this way the whole group--1ike a tableau vivant--projects a state of affairs" (4.0311). The Investigations is a critique of this "bad picture" of meaning, that is, of a view that incorporates the notion of picture to secure propositional meaning.

It is curious that the preface shows no hestitancy in invoking "pictures" to describe the form of a book which was "pictured differently at different times" ( $p$. 4). There is a difference between the pictureproposition of the Tractatus and the description of language "pictured" in the Investigations. We need to decide if the view of meaning implied in the latter work escapes the critique developed againgt the former.

The Tractatus and the passage removed from the Confessions depict the same "bad picture" of language. Wittgenstein writes that st. Augustine's "words - give us a particular picture of the essence of human language. It is this: the individual words in a language name objects--sentences are combinations of such names" (sec. 1). Philosophers behave like "savages, primitive people," because they have a primitive conception of how language works, or as Wittgenstein insinuates, a conception of a "primitive language-game" (sec. 194). Wittgenstein imagines a language-game in order to instruct us on how language really works. The particular gatne serve especially well because it plays at filling in the bad picture of st. Augustine. The game consists of four words: 'block', 'slab'. 'pillar', and 'beam' (sec. 2). Because the words all function in the same way, seemingly as names, and because they name building materials out of which complex constructions are made, the game seems to picture the Tractatus-view that language is conposed of simple names. The four words are called out by a builder in the order in which the assistant is to bring their objects. Since each word allegedly acts as a name, the relation between the names 18 shown in the order of their use.

Although we can characterize a Tractatus-theory of names and realations in terms of a simplified activity of building, the theory is incomplete. The Tractatus misses the significance of the game of building, the bigger picture or backgroud, surrounding and giving sense to the words and relations contained within the game. The calling out of 'slab'--which serves as a command as well as a name-would make no sense outside of its game. Likewise explanations of meaning which refer to objects succeed only if the over-all role of the word in the game is known. This is the point of the remark: "When one shews someone the king in chess and says: 'This is the king', this does not tell him the use of this piece.. . unless he is already master of a game" (sec. 31). Knowing the object to which a word refers does not by itself constitute knowing the 
grammar of the word. The picture theory neglects precisely this: meaning is determined by (though not identical with) circumstances of "use" (sec. 43).

Wittgenstein's description of "circuinstances of use" as a "complicated network of similarities, overlapping, and criss-crossing" (sec. 66) reminds us of his characterization of the text itself: "the very nature of the investigation . . . compels us to travel over a wide field of thought criss-cross in every direction" (p. v). The fiber metaphor depicts the unity resulting from the network of similarities: "In spinning a thread we twist fibre on fibre. And the strength of the thread does not reside in the fact that some fibre runs through its whole length, but in the overlapping of the fibres" (sec. 67). Again the interweaving of the Investigations' topics serves to an illustration.

Wittgenstein further illustrates the notion of circumstances of use with the metaphor of family resemblance: "I can think of no better expression to characterize these similarities than 'family resemblance': for the various resemblauces between members of a family. . overlap and crisis-cross in the same way" (sec. 67). It is because philosophers forget that words have a family of uses that they think that each word has one mysteriously attached meaning (sec. 116), that that meaning can be pindowned, and that meaning can be determinate and unambiguous.

In order for an album-theory of meaning to replace a picture-theory of meaning and preserve the possibility of determinate meaning, it must be possible to locate the proper circumstances for interpretting a picture, or a linguistic expression in general. otherwise, one is free to imagine alternative meanings (p. 54 (a)). Wittgenstein offers an example of how we might give sense to a picture by way of a further picture: "I see a picture which represents a smiling fact. What do I do if I take the smile now as a kind one, now as malicious: Don't I often imagine it with a context which is one either of kindness or malice? Thus I might supply the picture with the fancy (Vorstellen) that the smiler was smiling down on a child at play, or again on the suffering of an enemy" (sec. 539). The sense of any one of the "sketches" of the "Investigationg is already provided by the surrounding sketches. Recalling the metaphor of the preface, the picture of the landscape framed by the covers of the book (extended to include Tractatus) decermines the significane of the sketches contained within.

While the preface confesses that the Investigations falls short of its own rigorous demand for a finished picture of its subject--the defect is taken to be that of the draughtsman--the desire for complete depiction, or determinate meaning, persists. According to the Investigations proper, that clarity can be achieved, 
for example, by studying primitive language-games as simple models of linguistic use: "It disperses the fog to study the phenomena of language in primitive kinds of application in which one can conmand a clear view of the aim and functions of the words" (sec. 5). Without the possibility of a definite boundary for context, the fog which surrounds language could not be so forcefully and finally dispersed. Wittgenstein could not announce that "the clarity that we are aiming at is indeed complete clarity... [meaning] that the philosophical probleins should completely disappear" (sec. 33).

Wittgenstein's hope for coinplete clarity could not have been fulfilled, not even in the simple model of a primitive language-game. The process of deferring meaning from an isolated word or picture to its function in the larger story or album is an endless one. Section 359 (quoted in part above) goes on to say "I can also take the at first sight gracious situation [e.g., a kind smile] and interpret it differently [e.g. as malicious] by putting it into a wider context. - If no special circumstances reverse my interpretation I shall concelve a particular smile as kind, call it a 'kind' one, react correspondingly. ((Probability, frequency))" (sec. 539, 1talics mine). The addition of the second paragraph, however, suggests a more difficult problem than that of wider contexts. The revised paragraph, places the "special" case-we think of the less probably, malicious smile--in a "wider context" than the kind smile. The first paragraph, however, claims that the contexts differentiating the kind smile and the less probsbly malicious smile are distinct, but parallel. The fact that Wittgenstein preserves his first analysis of context along with the second and competing version opens the question of whether re-interpretation can be securred by a fuller understanding of a unified context. Wictgenstein offers no guarantee that the contexts surrounding a linguistic event are not distinct, competing and finally irresolvable.

The section ends with the hint, "((Probability. frequency))." guarantined in double parentheses. The hint serves to remind us that we ordinarily interpret isolated linguistic expressions according to their likely context. The queer parentheses, twice removing the hint from the body of the cext. quietly signal something suspicious in the need for the enclosed terms. For une thing, they are terms whose home is the empirical sciences, a place which is off-limits for a study which claims to be purely descriptive and unhypothetical (sec. 109).

Secondly, there is a problem covered over by Wittgenstein's intoduction of the notions of probability and frequency into his discussion of interpretation. Interpretations are not simply more or less likely, but are based upon context. Likelihood is it- 
self determined in relation to context. Since every meaning of a linguistic expression, however, depends upon some context, this context, as another expression, is subject to more extensive and even conflicting parallel contexts. For example, the Investigations requires another text, the Tractatus, in order to be correctly interpreted, but this supplement is not sufficient either. Some of the discussion has its motive in problems raised by Erege or Russell. How do we decide whom Wittgenstein is addressing? Can we include Schopenhauer whose influence is perhaps limited to style? Can we include Kant since wittgenstein seems to borrow distinctions from him--even if he claims never to have read any text of Kant's? The deferral of meaning from context to context is never completed."

The view of meaning which depends on the significance of context renders all determination of meaning indeterminate. Hope for a most comprehensive context which could perfectly constitute the scene for all the games played within may rest upon the notion of a form of life. And yet this notion, too, is only a move in a game, for example, the one dis-played in the Investigations. Any global concept achieves its use in a local game. The idealistic endeavor to construct a general category as the ilnal boundary for meaning must forget that this concept can be played out in an indefinite number of ways. It is possible for Wittgenstein to have arranged and sometimes cut down his sketroses for the Investigations because we can re-arrange and redivide the Iinguistic facts contained within any boundary in an indefinite number of ways. This is not to say that meaning is impossible but that it works through contexts playing against other contexts, contending for a determining role in a linguistic game. One might think that the imagining of larger or conflicting contexts misses the point that there are actual cases in which we say that now these words mean this." "Getting the picture" in a particular instance, however, requires making a decision about boundaries, and thus about what counts as "imagining" a wider or difficult context. This decision, like the sketches of the Investigations, is always subject to revision. There is no finally frameable picture of the landscape, or one which doesn't lack a part of the outside scene which can always enter into the picture. No text is complete by itself, no matter how comprehensive it is. Every picture calls for another one in order to settle its meaning. No meaning is finally settled.' 
'Ludwig Wittgenstein, Philosophical Investigations, trans., G. E. M. Anscombe (New York: Macmilian Publishing Co.. Inc., 1968), preface, p. v. All further references to this work appear in the text. Rererences to the German are from the following edition: Philosophische Untersuchungen (Erankfurt am Main: suhrkainp, 1977).

${ }^{2}$ Terry Eagleton in his article "Wittenstein's Eriends" (New Left Review, no 135, Sept.-Oct., 1982, p. 72) alludes to a possible deconstruction of Wittgenstein's Philosophical Investigations by exploiting Jacques Derrida "La pharmacie de platon," in La dessemination, (Paris: Editions du Seuil, 1972). The argument works by suggesting that since ordinary language is corruptible by bad philosophy, ordinary language must be always already philosophical. Eagleton criticizes Derrida for having a kind of negative metaphysics: all philosophical theses are left standing--even as their support is kicked. out from underneath. Eagleton writes: "Ihose post-structuralists who believe that in subverting the concepts of certainty they are putting the skids under metaphysics should perhaps consider that in this respect at least they are doing exactly the opposite" (p. 70). It would seem that the deconstructionists' only gain is the amendment to metaphysics that nothing is certain.

My paper attempts a deconstruction of the Investigations, but uses a different strategy than that recommended by Eagleton, since the latter examines the problem of indeterminate contexts. The sketches of the Investigations can never be finished, and this lack has philosophical and not just practical consequences. Deconstruction doesn't merely tack onto the Investigations" claim "probably, but uncertain." Wittgenstein, similarly, cannot simply add onto section 539 of his text the conment "((Probability. frequency))," and proceed as though the parenthetical clause were marginal and innocuous. As a supplement--I follow Derrida-the amendment disrupts the project itself.

'Ludwig Wittgenstein, Tractatus Logico-Philosophicus (New York: Routledge and Kegan Paul, 1971), 4.021. Further references to this work appear in the text.

"P. M. S. Hacker discusses the significance of what he translates as the "surview" for the Investigations in lnsight and lllusion (New York: Oxford University Press, 1972), p. 10 and pp. 113-14.

"The Investigations' ironic and aphoristic style and the use of "sketches" and metaphors appear out ot place with the call for complete clarity as a philo- 
sophical ideal. The excesses of the style illustrate the problem of indeterminate context and the possibility for reinterpretation which work against all texts.

Jack Canfield formulated these objections.

'The problem of incomplete determination is compounded by the consideration that the weave of the language-game--I extend wittgenstein's metaphor--works not only in the horizontal or contextual, dimension of the fiber (sec. 67), but also in the vertical dimension of metaphorical displacement, or substitution. Meaning is determined not only by what appears as part of the context, but also by what does not in fact accompany the text and yet is also relevant to its meaning. Displacements of ordinary language are patterns for philosophical displacement. The vertical dimension hides in the ironic and metaphoric style of the Investigations. Wittgenstein forgets the vertical dimension of his text, he overlooks the significarice of his use of a metaphor, even as he locates meaning in "language-ganes." (I thank Jack Canfield, Lewis Mackey, John Willett-Shoptaw, and especially Edwin Allaire for their generous and penetrating criticisms of my paper.) 